\title{
Estrogen-Metabolizing Gene COMT Polymorphism Synergistic APOE 84 Allele Increases the Risk of Alzheimer Disease
}

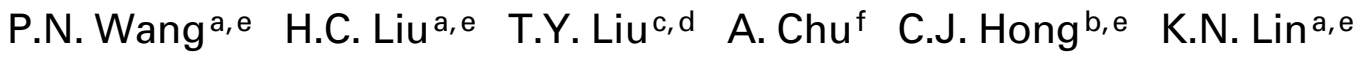 \\ C.W. Chic, d
}

a The Neurological Institute and Departments of ${ }^{b}$ Psychiatry and ${ }^{c}$ Medical Research and Education, Taipei Veterans General Hospital, and Institute of Pharmacology and eSchool of Medicine, National Yang-Ming University,

Taipei, Taiwan; fDepartment of Biomedical Engineering, Brown University, Providence, R.I., USA

\section{Key Words}

Estrogen - Alzheimer disease - Apolipoprotein E • Estrogen-metabolizing gene polymorphism

\begin{abstract}
Alzheimer disease (AD) is a polygenic multifactorial disorder. Several studies suggested that the neuroprotective effect of estrogen was based on an APOE-dependent mechanism. The goals of the current study were to determine if the genes involved in estrogen metabolism were linked to the risk of $A D$ and find out if there was an interaction between estrogen-metabolizing gene polymorphisms and the APOE $\varepsilon 4$ allele in the risk of prevalent AD. We investigated 66 patients with $A D$ and 86 age- and gender-matched normal subjects. The polymorphisms of APOE and estrogen-metabolizing genes CYP17, CYP1A1 and COMT were examined. No association was found between each estrogen-metabolizing gene polymorphism and AD. However, the COMT HH genotype and APOE $\varepsilon 4$ allele had a synergistic effect on the risk of AD. Taking subjects with $\varepsilon 4-\varepsilon 4-/ \mathrm{HH}-$ as reference, the risk of developing $A D$ in subjects with one $\varepsilon 4$ allele $(\varepsilon 4+\varepsilon 4-/ \mathrm{HH}-)$ was 2.6 (95\% confidence interval, $\mathrm{Cl}, 0.7-$
\end{abstract}

\section{KARGER}

Fax + 41613061234

E-Mail karger@karger.ch

www. karger.com (c) 2005 S. Karger AG, Basel

Accessible online at: www. karger.com/dem
9.1); however, the risk in subjects with both $\mathrm{HH}$ and one $\varepsilon 4(\varepsilon 4+\varepsilon 4-/ \mathrm{HH}+)$ increased to $3.6(95 \% \mathrm{Cl} 1.2-10.6)$. The subjects with homozygous 84 still had the highest risk in developing AD (odds ratio 6.6, 95\% $\mathrm{Cl}$ 0.6-69.6). The $\mathrm{p}$ value of the linear trend test for this regression model was $\mathbf{0 . 0 0 4}$. It is possible that a high metabolism of estrogen by COMT may have reduced the protective effect of estrogen in AD. Further studies to clarify this interaction may improve our understanding of the generic risks for AD.

Copyright @ 2005 S. Karger AG, Basel

\section{Introduction}

Epidemiology data indicate that elderly women have a higher risk of developing Alzheimer disease (AD) than men [1]. The dramatic decrease in endogenous estrogen levels after the menopause may contribute to the development of AD in these women [2]. Several mechanisms have been proposed for the neuroprotective effects of estrogen, and they include antioxidant, anti-inflammatory and antiexcitotoxic effects, promotion of neurite outgrowth and synaptogenesis [3-7].

Dr. Chin-Wen Chi

Department of Medical Research and Education

Taipei Veterans General Hospital, Taipei, Taiwan (ROC)

Tel. +8862 28757627, Fax +886228751562

E-Mail cwchi@vghtpe.gov.tw 
Estrogen effects on the central nervous system are modulated via the estrogen receptors and/or estrogen metabolites. Estrogen receptor $\alpha$ and $\beta$ polymorphisms were found to associate with $\mathrm{AD}$ [4-7] or cognitive impairment [8]. The polymorphisms of the estrogen-metabolizing genotype were related to the serum concentration and activity of estrogen [9]. Previous studies found that genes involved in estrogen biosynthesis (cytochrome P450c17a; CYP17), hydroxylation (cytochrome P4501A; CYP1A1) and inactivation of the reactive metabolites (catechol-Omethyltransferase; COMT) were associated with an elevated risk of breast cancer $[10,11]$. Since the relationship between genes involved in estrogen metabolism and AD is not clear, we proposed that estrogen-metabolizing gene polymorphisms might be correlated with the risk of $\mathrm{AD}$.

CYP17 encodes the enzyme cytochrome P450c17, which catalyzes steroid 17 $\alpha$-hydroxylase and 17-20 lyase activities at key points in estrogen biosynthesis. There are $\mathrm{A} 1$ (wt) and A2 (vt) genotypes, and A2 is associated with elevated levels of circulating estradiol in young women [12]. CYP1A1 is an important enzyme involved in hydroxylation of estrogen. CYP1A1 activity was more inducible in lymphocytes with the $\mathrm{m} 1 \mathrm{vt}$ genotype than with the wt genotype [13]. O-Methylation mediation by COMT is an important mechanism for inactivating estrogen. The L (low activity) allele, in contrast to the $\mathrm{H}$ (high activity) allele, links to low COMT activity and results in accumulation of catechol estrogen [14]. All of these genotype polymorphisms were correlated with the risk of breast cancer [10].

$\mathrm{AD}$ is a polygenic multifactorial disorder determined by the interaction of genetic, metabolic and environmental factors. Several genes were associated with familial and sporadic AD. The apolipoprotein E (APOE) $\varepsilon 4$ allele is an important risk factor for $\mathrm{AD}$, but it is neither essential nor sufficient for the development of AD [15]. Other genes or metabolic factors may modify the $\varepsilon 4$ effect to initiate the pathogenesis of AD. Several studies showed an interaction between estrogen and APOE [16-18]. Estradiol promoted synaptic sprouting via an APOE-dependent mechanism, and the neuroprotective effect of estradiol was seen only in APOE-bearing mice [19]. The protective effect of estrogen replacement therapy on cognitive decline was most marked in non- $\varepsilon 4$ bearers [16].

In the present study, we evaluated (1) if the genes involved in estrogen metabolism were linked to the risk of $\mathrm{AD},(2)$ if there was an interaction between APOE and estrogen metabolism genotype polymorphism and (3) if the interaction would influence the risk of developing $\mathrm{AD}$.

\section{Materials and Methods}

\section{Subjects}

The study was conducted at Taipei Veterans General Hospital, which is a teaching hospital in northern Taiwan. Patients were selected from subjects participating in our longitudinal study investigating cognitive decline in the normal elderly, mild cognitive impairment and AD. From January 2002 to December 2002, we consecutively enrolled the possible candidates from our neurology clinic, and informed consents were obtained from all subjects or their caregivers. All AD patients met the criteria of the National Institute of Neurological and Communicative Disorders and Stroke and the Alzheimer's and Related Disorders Association (NINCDS-ADRDA) [20] for probable AD. Neurological examinations, laboratory tests and neuroimaging evaluation (brain computerized tomography or magnetic resonance imaging) were performed to exclude patients with secondary causes of dementia, such as vascular dementia, Parkinson's disease, hypothyroidism, vitamin $\mathrm{B}_{12}$ deficiency and syphilis. All AD patients enrolled in this study were sporadic cases without a family history of dementia. All control subjects were genetically unrelated to the patients. They were spouses of the AD patients or individuals who presented to our neurological clinic due to other neurological diseases without brain lesions. Neuropsychological assessments and clinical interviews were performed with every control subject to confirm the absence of cognitive deficits. Sixty-six AD patients were consecutively recruited, and 86 age- and gendermatched normal controls were selected to enter the analysis.

\section{Estrogen-Metabolizing and APOE Gene Polymorphisms}

Blood samples were collected by venipuncture into EDTA-2Na vacutubes. Genomic DNA was isolated from peripheral white blood cells using standard phenol methods. The polymerase chain reactionrestriction fragment length polymorphism assays were used to determine the APOE and estrogen-metabolizing gene polymorphisms. The APOE genotyping was carried out using standard protocols [21]. Genotypes of CYP17, CYP1A1 and COMT were determined by digestion with restriction enzymes MspAI, MspI and Hsy92II, respectively [9]. The restriction fragment length polymorphisms of CYP17, CYP1A1 and COMT were coded as A1/A2, wt/vt and H/L, respectively. $\mathrm{A} 2$, vt and $\mathrm{L}$ stand for the presence of the restriction site, and $\mathrm{A} 1$, wt and $\mathrm{H}$ for its absence.

\section{Statistical Analysis}

The frequency distribution of the APOE $\varepsilon 4$ allele and all estrogen metabolism genotype polymorphisms in $\mathrm{AD}$ versus control subjects were compared using the standard $\chi^{2}$ test. The effects of homozygous CYP17 (A1A1 or A2A2), CYP1A1 (wtwt or vtvt) and COMT (HH or $\mathrm{LL}$ ) genotype on the risk of developing $\mathrm{AD}$ were checked by the $\chi^{2}$ test. Since it was reported that the effect of estrogen might exist only in $\varepsilon 4$ carriers, we examined the interactions between the $\varepsilon 4$ allele and estrogen metabolism polymorphisms. The combined effects of APOE and estrogen metabolism genotype polymorphisms in the risk of $\mathrm{AD}$ were evaluated by multinomial logistic regression analysis, and odds ratios were calculated. When significance was found, a test for linear trend was also applied. All statistical analyses were performed by SPSS for Windows, release 11.0 (SPSS Inc., Chicago, Ill., USA). A p value $<0.05$ was defined as statistically significant. 


\section{Results}

Sixty-six AD and 86 control patients were recruited for this study (table 1). The mean score of the Mini-Mental State Examination [22] of our AD patients was $17.4 \pm$ 6.9. Most (73.8\%) of them had mild AD with the Clinical Dementia Rating [23] = 1, and the mean Clinical Dementia Rating was $1.3 \pm 0.6$ (range $1-3$ ).

As we had reported previously [21], the frequency of the APOE $\varepsilon 4$ allele was higher in AD than control subjects in this study. The odds ratio of developing AD was 3.0 (95\% confidence interval, CI, 1.4-6.6) for subjects with one $\varepsilon 4$ allele and $4.6(95 \% \mathrm{CI} 0.9-24.9)$ for those with two $\varepsilon 4$ alleles. The small case number (5 subjects) with homozygous $\& 4$ may have influenced the power of the statistical analysis.

The allele and genotype distributions of estrogen CYP17, CYP1A1 and COMT polymorphisms were similar in $\mathrm{AD}$ and control subjects (table 1). The homozygous genotypes of CYP17, CYP1A1 and COMT were not correlated with $\mathrm{AD}$ either.

While investigating the combined effects of estrogen metabolizing gene polymorphisms and APOE $\& 4$ allele, we found no combined effects of CYP17, CYP1A1 polymorphism and $\varepsilon 4$ genotype. However, a weak but significant enhancer activity of homozygous COMT HH genotype to $\varepsilon 4$ was observed (table 2). Taking subjects without $\varepsilon 4$ as reference, the odds ratio of developing $\mathrm{AD}$ in subjects with at least one $\varepsilon 4$ ( $\varepsilon 4$ carriers) but without $\mathrm{HH}$ was 3.2 (95\% CI 1.0-9.8), and the risk in $\varepsilon 4$ carriers plus $\mathrm{HH}$ genotype increased to 3.5 (95\% CI 1.2-10.0). The $\mathrm{p}$ value of the linear trend test for this regression model was 0.016 .

We further used a multivariate logistic regression model to evaluate the $\varepsilon 4$ dose effect on the interaction between COMT $\mathrm{HH}$ and $\varepsilon 4$. We subgrouped all subjects into 6 groups: neither $\varepsilon 4$ nor $\mathrm{HH}(\varepsilon 4-\varepsilon 4-/ \mathrm{HH}-)$, no $\varepsilon 4$ but with $\mathrm{HH}(\varepsilon 4-\varepsilon 4-/ \mathrm{HH}+)$, one $\varepsilon 4$ but no $\mathrm{HH}(\varepsilon 4+\varepsilon 4-/ \mathrm{HH}-)$, one $\varepsilon 4$ with $\mathrm{HH}(\varepsilon 4+\varepsilon 4-/ \mathrm{HH}+)$, two $\varepsilon 4$ but no $\mathrm{HH}$ $(\varepsilon 4+\varepsilon 4+/ \mathrm{HH}-)$ and two $\varepsilon 4$ with $\mathrm{HH}(\varepsilon 4+\varepsilon 4+/ \mathrm{HH}+)$. The odds ratio calculated by logistic regression is shown in table 2. Taking the $\varepsilon 4-\varepsilon 4-/ H H-$ as reference, the risk of developing $\mathrm{AD}$ in subjects with one $\varepsilon 4$ allele but without $\mathrm{HH}(\varepsilon 4+\varepsilon 4-/ \mathrm{HH}-)$ was 2.6 (95\% CI 0.7-9.1). However, the risk in subjects with both $\mathrm{HH}$ and one $\varepsilon 4(\varepsilon 4+\varepsilon 4-/$ $\mathrm{HH}+)$ increased to $3.6(95 \% \mathrm{CI} 1.2-10.6)$. The subjects with homozygous $\varepsilon 4$ still had the highest risk to develop $\mathrm{AD}$ (odds ratio 6.6, 95\% CI 0.6-69.6). The $\mathrm{p}$ value of the linear trend test for this regression model was 0.004 .
Table 1. Demographic data and distribution of genotype polymorphisms of estrogen-metabolizing genes and APOE

\begin{tabular}{|c|c|c|c|}
\hline & $\begin{array}{l}\mathrm{AD} \\
(\mathrm{n}=66)\end{array}$ & $\begin{array}{l}\text { Controls } \\
(\mathrm{n}=86)\end{array}$ & $\mathrm{p}$ value \\
\hline Age, years & $73.3 \pm 7.6$ & $72.6 \pm 8.3$ & 0.612 \\
\hline Gender $(\mathrm{M} / \mathrm{F})$ & $33 / 33$ & $44 / 42$ & 1.000 \\
\hline MMSE* & $17.4 \pm 6.9$ & $28.2 \pm 5.5$ & $<0.001$ \\
\hline $\mathrm{CDR}^{*}$ & $1.3 \pm 0.6$ & $0 \pm 0.0$ & $<0.001$ \\
\hline APOE $\varepsilon 4, \%$ & & & 0.005 \\
\hline No $\varepsilon 4$ & 57.6 & 81.4 & \\
\hline One $\varepsilon 4$ & 34.8 & 16.3 & \\
\hline Two $\varepsilon 4$ & 7.6 & 2.3 & \\
\hline \multicolumn{4}{|l|}{ COMT, $\%$} \\
\hline $\mathrm{HH}$ & 57.9 & 55.8 & 0.955 \\
\hline HL & 35.1 & 36.0 & \\
\hline LL & 7.0 & 8.1 & \\
\hline $\mathrm{H}$ allele & 75.5 & 73.8 & 0.411 \\
\hline \multicolumn{4}{|l|}{ CYP17, \% } \\
\hline A1A1 & 30.9 & 41.7 & 0.316 \\
\hline $\mathrm{A} 1 \mathrm{~A} 2$ & 54.5 & 41.7 & \\
\hline $\mathrm{A} 2 \mathrm{~A} 2$ & 14.5 & 16.7 & \\
\hline A1 allele & 58.2 & 62.6 & 0.059 \\
\hline \multicolumn{4}{|l|}{ CYP1A1, \% } \\
\hline wtwt & 19.6 & 21.4 & 0.940 \\
\hline wtvt & 51.8 & 52.4 & \\
\hline vtvt & 28.6 & 26.2 & \\
\hline w allele & 45.5 & 47.6 & 0.370 \\
\hline
\end{tabular}

MMSE $=$ Mini-Mental State Examination $;$ CDR $=$ Clinical Dementia Rating. ${ }^{*} \mathrm{p}<0.05$.

Table 2. The combined effect of APOE $\varepsilon 4$ and estrogen-metabolizing COMT HH genotype on the risk of $\mathrm{AD}$

\begin{tabular}{llll}
\hline & OR & $95 \% \mathrm{CI}$ & $\mathrm{p}$ value \\
\hline$\varepsilon 4$ carrier and HH & & & \\
$\varepsilon 4-/ \mathrm{HH}-(\mathrm{n}=49)$ & 1 & & \\
$\varepsilon 4-/ \mathrm{HH}+(\mathrm{n}=60)$ & 1.1 & $0.5-2.5$ & 0.859 \\
$\varepsilon 4+/ \mathrm{HH}-^{*}(\mathrm{n}=18)$ & 3.2 & $1.0-9.8$ & 0.050 \\
$\varepsilon 4+/ \mathrm{HH}+*(\mathrm{n}=25)$ & 3.5 & $1.2-10.0$ & 0.021 \\
\hline$\varepsilon 4$ dose effect and $\mathrm{HH}$ & & & \\
$\varepsilon 4-\varepsilon 4-/ \mathrm{HH}-(\mathrm{n}=49)$ & 1 & & \\
$\varepsilon 4-\varepsilon 4-/ \mathrm{HH}+(\mathrm{n}=60)$ & 1.1 & $0.5-2.5$ & 0.859 \\
$\varepsilon 4+\varepsilon 4-/ \mathrm{HH}-(\mathrm{n}=14)$ & 2.6 & $0.7-9.1$ & 0.140 \\
$\varepsilon 4+\varepsilon 4-/ \mathrm{HH}+*(\mathrm{n}=23)$ & 3.6 & $1.2-10.6$ & 0.021 \\
$\varepsilon 4+\varepsilon 4+/ \mathrm{HH}-(\mathrm{n}=4)$ & 6.6 & $0.6-69.6$ & 0.114 \\
$\varepsilon 4+\varepsilon 4+/ \mathrm{HH}+(\mathrm{n}=2)$ & 2.2 & $0.1-38.0$ & 0.584 \\
\hline
\end{tabular}

$\mathrm{HH}+=$ Carriers of the homozygous $\mathrm{HH}$ genotype; $\mathrm{HH}-=$ carriers of $\mathrm{HL}$ or LL; OR = odds ratio. Odds ratios and $95 \%$ CIs were calculated by logistic regression models. $* \mathrm{p}<0.05$. 


\section{Discussion}

In this study, we detected a synergetic effect of homozygous COMT HH genotype and APOE $\varepsilon 4$ allele. APOE $\varepsilon 4$ is a known genetic risk factor for $\mathrm{AD}$ and preclinical cognitive decline [24]. However, individuals bearing one or two $\varepsilon 4$ alleles do not always develop AD. Therefore, other factors may modulate the consequence of the $\varepsilon 4$ allele.

Several lines of evidence support the interaction between estrogen and APOE. Epidemiological studies reported an interaction between gender and APOE with women having a higher $\varepsilon 4$-associated risk of AD than men [25]. APOE also influenced the response of estrogen therapy. The protective effect of estrogen in cognitive decline

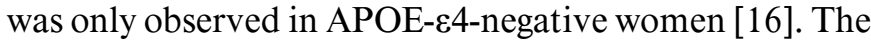
animal studies showed that estrogen modulated the expression of APOE in brain tissues [17] and estradiol promoted synaptic sprouting by an APOE-dependent mechanism [19].

Women with AD had lower estradiol levels than nondemented women [26]. Serum estradiol levels of individuals may be determined by genotype polymorphisms of the estrogen-metabolizing genes. Three hours after a single dose $(2 \mathrm{mg})$ of oral estradiol, serum estradiol levels were significantly higher in women with the COMT LL genotype and the COMT HL genotype than women with the COMT HH genotype [27]. Therefore, polymorphisms of metabolizing genes COMT HH may also play a role in the development of AD through a lower serum estrogen concentration.

We did not find a direct correlation between the COMT HL polymorphism and AD. Nevertheless, we discovered that COMT HH had a synergetic effect with APOE $\varepsilon 4$. A previous study focused on the estrogen receptor 1 (ESR1) gene polymorphism also had a similar finding [5]. Mattila et al. [5] found that the genotype and allele distributions of the ESR1 polymorphisms did not differ significantly between Swedish AD patients and controls; however, an interaction of ESR 1 xx genotype and APOE $\varepsilon 4$ allele was noted in the logistic regression analysis. The $\varepsilon 4$ allele was still the greatest risk factor for $\mathrm{AD}$ in our study. Regardless of the status of the HH genotype, the odds ratio of developing $\mathrm{AD}$ was 3.0 (95\% CI 1.4-6.6) for subjects with one $\varepsilon 4$ allele. When the factor of $\mathrm{HH}$ genotype is included in the logistic analysis, the risk of subjects with one $\varepsilon 4$ allele but without $\mathrm{HH}(\varepsilon 4+\varepsilon 4-/ \mathrm{HH}-)$ to develop $\mathrm{AD}$ decreased to 2.6 (95\% CI 0.7-9.1). However, in subjects possessing both $\mathrm{HH}$ and one $\varepsilon 4(\varepsilon 4+\varepsilon 4-/$ $\mathrm{HH}+)$, the odds ratio increased to 3.6 (95\% CI 1.2-10.6).
Based on these results, we can assume that the existence of the COMT HH genotype was an important modulating factor for the increased risk of developing AD.

The subjects with homozygous $\varepsilon 4$ still had the highest risk for developing $\mathrm{AD}$ (odds ratio $=6.6,95 \%$ CI 0.6 69.6). There were only 2 subjects with both $\mathrm{HH}$ and homozygous $\varepsilon 4(\mathrm{HH}+/ \varepsilon 4+\varepsilon 4+)$, and this may have interfered with the statistical power in this group; thus, a decreased risk was noted in this homozygous group.

The other two estrogen-metabolizing gene polymorphisms (CYP17 and CYP1A1) did not show any correlation with $\mathrm{AD}$. Breast cancer risk associated with estrogenmetabolizing genes also revealed that the COMT genotype polymorphism was the most marked susceptibility gene [10]. The odds ratio of the COMT LL genotype to develop breast cancer was 4.0, but the odds ratio for CYP1A1 and CYP17 was only 1.8 and 1.2. From the single-dose estradiol challenge study, we know that individuals with the COMT LL genotype have the highest serum estradiol concentration and the ones with the COMT HH genotype have the lowest concentration [27]. COMT polymorphism may be an essential factor determining the serum concentration and activity of estradiol.

Whether the estrogen genetic effect presents in both sex groups or is restricted to just one of them is another interesting question. Brandi et al. [7] disclosed an increased risk for $\mathrm{AD}$ in individuals bearing the APOE $\varepsilon 4 \varepsilon 4$ and PPXX ER $\alpha$ genotypes, whereas Mattila et al. [5] found that only women bearing at least one $\varepsilon 4$ allele and the PPXX ER $\alpha$ genotypes had an increased risk for AD. The small sample size of our study does not allow further stratification according to gender; thus, it limited the use of a more powerful statistical test. However, based on the findings of a pronounced increase in nuclear estrogen receptor expression in both sexes of $\mathrm{AD}$ patients [28] and polymorphisms in the brain aromatase gene CYP19 showing an increased risk for AD in both men and women [29], the genetic modulating effect found in our study may take place in $\mathrm{AD}$ patients irrespective of gender.

Some previous epidemiological studies revealed a protective effect of estrogen replacement therapy (ERT) in the prevention of $\mathrm{AD}$ [30]. However, ERT was not effective in treating $\mathrm{AD}[31,32]$. Recently, the Women's Health Initiative Trial demonstrated a detrimental effect of estrogen plus progestin therapy in incidental dementia [33]. Genetic factors may play an important role in these controversial results. In studies concerning cholesterol control and atherosclerosis, the effect of ERT is especially beneficial in subjects with no APOE 4 allele [33, 34]. Comparable findings could also be expected in the corre- 
lation between ERT and cognition. One study reported a protective effect of estrogen in cognitive decline only observed in APOE- 84 -negative women [16]. Estrogen receptor genotype and estrogen-metabolizing genotype may also affect the results of ERT in AD.

Currently, acetylcholine esterase (AChE) inhibitors are the main treatment for AD. Unfortunately, this approach is helpful only in some AD patients, and it is difficult to identify which patients respond to these drugs. Genetic variations may influence the beneficial effect of $\mathrm{AChE}$ inhibitors. An allele dose effect of APOE $\varepsilon 4$ was inversely correlated with the choline acetyltransferase activity and clinical response to tacrine [35]. Estrogen also affected the activity of choline acetyltransferase and AChE [36, 37]. Based on the interaction of APOE $\varepsilon 4$ and COMT HH genotype, perhaps one can identify the subjects that may benefit more from $\mathrm{AChE}$ inhibitors.

There are some limitations to our study that must be addressed. Firstly, this is a case-control study, and the number of cases was small. The data are very preliminary. A larger case-control or community-based study in differ- ent populations may provide more information. Secondly, we did not measure the serum concentration of estradiol, and the possible interaction between estradiol level, APOE and estrogen-metabolizing genotype is unknown. Thirdly, none of our patients received ERT, and their history of ERT was not available. This is a possible confounding bias.

In conclusion, we identified a synergistic effect of the estrogen-metabolizing genotype COMT HH and APOE $\varepsilon 4$ in this preliminary study. Further research is needed to confirm this correlation and its application to the treatment of AD. These results will help to identify individuals who can be effectively treated with estrogen or AChE inhibitors.

\section{Acknowledgements}

This study was supported in part by grants from the National Science Council (NSC 87-2314-B-75-015 and NSC 92-3112-B010004), the National Health Research Institute (DOH 87-HR-604) and Taipei Veterans General Hospital (VGH-92-377-2).

\section{References}

1 Barrett AM: Probable Alzheimer's disease: Gender-related issues. J Gend Specif Med 1999;2:55-60.

$>2$ Gandy S: Estrogen and neurodegeneration. Neurochem Res 2003;28:1003-1008.

-3 Norbury R, Cutter WJ, Compton J, Robertson DM, Craig M, Whitehead M, Murphy DG: The neuroprotective effects of estrogen on the aging brain. Exp Gerontol 2003;38:109-117.

$\checkmark 4$ Lambert JC, Harris JM, Mann D, Lemmon H, Coates J, Cumming A, St-Clair D, Lendon C: Are the estrogen receptors involved in $\mathrm{Alz}$ heimer's disease? Neurosci Lett 2001;306:193197.

$\checkmark 5$ Mattila KM, Axelman K, Rinne JO, Blomberg M, Lehtimaki T, Laippala P, Roytta M, Viitanen M, Wahlund L, Winblad B, Lannfelt L: Interaction between estrogen receptor 1 and the epsilon4 allele of apolipoprotein $\mathrm{E}$ increases the risk of familial Alzheimer's disease in women. Neurosci Lett 2000;282:45-48.

-6 Ji Y, Urakami K, Wada-Isoe K, Adachi Y, Nakashima K: Estrogen receptor gene polymorphisms in patients with Alzheimer's disease, vascular dementia and alcohol-associated dementia. Dement Geriatr Cogn Disord 2000 11:119-122.

7 Brandi ML, Becherini L, Gennari L, Racchi M, Bianchetti A, Nacmias B, Sorbi S, Mecocci P. Senin U, Govoni S: Association of the estrogen receptor alpha gene polymorphisms with sporadic Alzheimer's disease. Biochem Biophys Res Commun 1999;265:335-338.
8 Yaffe K, Lui LY, Grady D, Stone K, Morin P: Estrogen receptor 1 polymorphisms and risk of cognitive impairment in older women. Biol Psychiatry 2002;51:677-682.

-9 Gorai I, Tanaka K, Inada M, Morinaga H, Uchiyama Y, Kikuchi R, Chaki O, Hirahara F: Estrogen-metabolizing gene polymorphisms, but not estrogen receptor-alpha gene polymorphisms, are associated with the onset of menarche in healthy postmenopausal Japanese women. J Clin Endocrinol Metab 2003;88: 799-803.

10 Huang CS, Chern HD, Chang KJ, Cheng CW, Hsu SM, Shen CY: Breast cancer risk associated with genotype polymorphism of the estrogen-metabolizing genes CYP17, CYP1A1, and COMT: A multigenic study on cancer susceptibility. Cancer Res 1999;59:4870-4875.

11 Mitrunen K, Hirvonen A: Molecular epidemiology of sporadic breast cancer: The role of polymorphic genes involved in oestrogen biosynthesis and metabolism. Mutat Res 2003; 544:9-41.

12 Picado-Leonard J, Miller WL: Cloning and sequence of the human gene for P450c17 (steroid 17 alpha-hydroxylase/17,20 lyase): Similarity with the gene for P450c21. DNA 1987;6:439448.

13 Landi MT, Bertazzi PA, Shields PG, Clark G, Lucier GW, Garte SJ, Cosma G, Caporaso NE: Association between CYP1A1 genotype, mRNA expression and enzymatic activity in humans. Pharmacogenetics 1994;4:242-246.
14 Yager JD, Liehr JG: Molecular mechanisms of estrogen carcinogenesis. Annu Rev Pharmacol Toxicol 1996;36:203-232.

15 Kakulas BA, van Bockxmeer FM: Apolipoprotein E genotyping in the diagnosis of Alzheimer's disease: A cautionary view. Ann Neurol 1995;38:966-967.

16 Yaffe K, Haan M, Byers A, Tangen C, Kuller L: Estrogen use, APOE, and cognitive decline: Evidence of gene-environment interaction. Neurology 2000;54:1949-1954.

17 Srivastava RA, Srivastava N, Averna M, Lin RC, Korach KS, Lubahn DB, Schonfeld G: Estrogen up-regulates apolipoprotein E (ApoE) gene expression by increasing ApoE mRNA in the translating pool via the estrogen receptor alpha-mediated pathway. J Biol Chem 1997; 272:33360-33366.

18 Teter B, Harris-White ME, Frautschy SA, Cole GM: Role of apolipoprotein $\mathrm{E}$ and estrogen in mossy fiber sprouting in hippocampal slice cultures. Neuroscience 1999;91:1009-1016.

19 Stone DJ, Rozovsky I, Morgan TE, Anderson $\mathrm{CP}$, Finch CE: Increased synaptic sprouting in response to estrogen via an apolipoprotein $\mathrm{E}$ dependent mechanism: Implications for Alzheimer's disease. J Neurosci 1998;18:31803185 . 
20 McKhann G, Drachman D, Folstein M, Katzman R, Price D, Stadlan EM: Clinical diagnosis of Alzheimer's disease: Report of the NINCDS-ADRDA Work Group under the auspices of Department of Health and Human Services Task Force on Alzheimer's Disease. Neurology 1984;34:939-944.

-21 Hong CJ, Liu TY, Liu HC, Wang SJ, Fuh JL, Chi CW, Lee KY, Sim CB: Epsilon 4 allele of apolipoprotein E increases risk of Alzheimer's disease in a Chinese population. Neurology 1996;46:1749-1751.

-22 Folstein MF, Folstein SE, McHugh PR: 'Minimental state'. A practical method for grading the cognitive state of patients for the clinician. J Psychiatr Res 1975;12:189-198.

$\checkmark 23$ Hughes CP, Berg L, Danziger WL, Coben LA, Martin RL: A new clinical scale for the staging of dementia. Br J Psychiatry 1982;140:566572.

-24 Bretsky P, Guralnik JM, Launer L, Albert M, Seeman TE: The role of APOE-epsilon4 in longitudinal cognitive decline: MacArthur Studies of Successful Aging. Neurology 2003;60:1077_ 1081 .

-25 Mortensen EL, Hogh P: A gender difference in the association between APOE genotype and age-related cognitive decline. Neurology 2001; 57:89-95.
26 Manly JJ, Merchant CA, Jacobs DM, Small SA, Bell K, Ferin M, Mayeux R: Endogenous estrogen levels and Alzheimer's disease among postmenopausal women. Neurology 2000;54: 833-837.

27 Worda C, Sator MO, Schneeberger C, Jantschev T, Ferlitsch K, Huber JC: Influence of the catechol-O-methyltransferase (COMT) codon 158 polymorphism on estrogen levels in women. Hum Reprod 2003;18:262-266.

28 Ishunina TA, Swaab DF: Increased expression of estrogen receptor alpha and beta in the nucleus basalis of Meynert in Alzheimer's disease. Neurobiol Aging 2001;22:417-426.

29 Iivonen S, Corder E, Lehtovirta M, Helisalmi S, Mannermaa A, Vepsalainen S, Hanninen T, Soinen H, Hiltunen M: Polymorphism in the CYP19 gene confer increased risk for Alzheimer disease. Neurology 2004;62:1170-1176.

-30 Yaffe K, Sawaya G, Lieberburg I, Grady D: Estrogen therapy in postmenopausal women: Effects on cognitive function and dementia. JAMA 1998;279:688-695.

31 Wang PN, Liao SQ, Liu RS, Liu CY, Chao HT, Lu SR, Yu HY, Wang SJ, Liu HC: Effects of estrogen on cognition, mood, and cerebral blood flow in AD: A controlled study. Neurology 2000;54:2061-2066.

32 Henderson VW, Paganini-Hill A, Miller BL, Elble RJ, Reyes PF, Shoupe D, McCleary CA, Klein RA, Hake AM, Farlow MR: Estrogen for Alzheimer's disease in women: Randomized, double-blind, placebo-controlled trial. Neurology 2000;54:295-301.
33 Shumaker SA, Legault C, Rapp SR, Thal L, Wallace RB, Ockene JK, Hendrix SL, Jones BN 3rd, Assaf AR, Jackson RD, Kotchen JM, Wassertheil-Smoller S, Wactawski-Wende $\mathrm{J}$ : Estrogen plus progestin and the incidence of dementia and mild cognitive impairment in postmenopausal women: The Women's Health Initiative Memory Study: A randomized controlled trial. JAMA 2003;289:2651-2662.

34 Lehtimaki T, Dastidar P, Jokela H, Koivula T, Lehtinen S, Ehnholm C, Punnonen R: Effect of long-term hormone replacement therapy on atherosclerosis progression in postmenopausal women relates to functional apolipoprotein $\mathrm{E}$ genotype. J Clin Endocrinol Metab 2002;87; 4147-4153.

35 Poirier J, Delisle MC, Quirion R, Aubert I, Farlow M, Lahiri D, Hui S, Bertrand P, Nalbantoglu J, Gilfix BM, et al: Apolipoprotein E4 allele as a predictor of cholinergic deficits and treatment outcome in Alzheimer disease. Proc Natl Acad Sci USA 1995;92:12260-12264.

36 Luine VN, McEwen BS: Sex differences in cholinergic enzymes of diagonal band nuclei in the rat preoptic area. Neuroendocrinology 1983; 36:475-482.

37 Luine VN, Renner KJ, Heady S, Jones KJ: Age and sex-dependent decreases in ChAT in basal forebrain nuclei. Neurobiol Aging 1986;7:193198. 